\title{
A Surrogate Model for Simulation-optimization of Aquifer Systems Subjected to Seawater Intrusion
}

\author{
Mohammed S. Hussain, Akbar A. Javadi, Alireza Ahangar-Asr, Razieh Farmani
}

\begin{abstract}
This study presents the application of Evolutionary Polynomial Regression (EPR) as pattern recognition system to predicate the numerical results of nonlinear and computationally complex aquifer system threatened by seawater intrusion (SWI). The developed EPR models are also linked with the multi objective genetic algorithm to test the efficiency of different arrangements of hydraulic barriers considered to control SWI. For this purpose the developed EPR model for each control scenario are trained and tested on the set of different pumping patterns as inputs and the corresponding set of numerically calculated outputs. The results are compared with those obtained by direct linking of the numerical simulation model with the optimization tool. These two strategies of the simulation-optimization (S/O) show excellent agreement on the obtained set of optimal solutions.

The three combined management scenarios have been considered which involve the effects of both abstraction and recharge barriers simultaneously. Minimization of both the economic cost of management process and the salinity level in the aquifer are the two objective functions used for evaluating the cost efficiency of each management scenario studied. By considering the effects of the unsaturated zone, the subsurface pond is used to collect the water and to artificially recharge the aquifer in these scenarios. The main distinguish feature of EPR emerges in its application as metamodel in $\mathrm{S} / \mathrm{O}$ process where it reduces the overall computational complexity significantly. The results also suggested that the application of cheap source of water such as the TWW and/or storm water instead of desalinated water coupled with continues abstraction water followed by its application for human consumption or irrigation after desalination as most cost effective method to control SWI.

The effects of supplying these different external sources of recharge water and also the effects of different recovery ratios of desalination plant on the optimal results are also presented through sensitivity studies by using the developed methodology.
\end{abstract}

Keywords: seawater intrusion; management scenarios, optimization; surrogate model, EPR

\section{Introduction}

Under natural conditions, the replacement of freshwater in coastal aquifers by the seawater due to density-dependent landward movement of saline water body into the freshwater is known as SWI. Since the 1960s, the simulation of the SWI as major problem threatening groundwater resources have been extensively started to develop. In early stages of this development the analytical and semi analytical solutions have been used for simulating the progress of SWI. Generally, the shape of the interaction zone between the fresh and saline water bodies are interpreted using two different theories, sharp interface and dispersion interface theories. In sharp interface theory the two liquids considered as two immiscible fluids with mixing zone has the relatively smaller width than the aquifer thickness (Das and 
Datta, 1999a; Kacimov and Sherif, 2006). However, as a result of hydrodynamic dispersion, which is the combination of mechanical dispersion and physico-chemical dispersion (molecular diffusion), the contact zone between the two fluids takes the form of a transition zone (dispersive zone), the thickness of which depends upon the hydrodynamics of the aquifer Sherif et al. (1990b) and Bear and Zhou (2007).

The natural hydrostatic equilibrium state between freshwater and saline water can be disturbed by exploitation of groundwater in aquifer (Sherif et al., 1990a). The SWI is exacerbated as outcome of this long-term disturbance which eventually leads to other problems such as decrease of fresh water availability, human health and ecosystem damage (Patel and Shah, 2008). Therefore it would be necessary to predict the future sustainability of water supplies and the movement of the saltwater front. Based on these two forms of saline/freshwater interface, in last decades, several methods have been proposed to simulate the SWI process using different analytical, numerical and physical approaches. Generally the sharp interface is the main theory used as a foundation in majority of the analytical simulations. It is used for quick estimation of the equilibrium location of interface. However, SWI is a highly nonlinear and density-dependent process. Therefore, spatial and temporal simulation of this process will require the use of numerical methods to solve the nonlinear governing equations of flow and solute transport simultaneously through saturated/unsaturated porous media. A general overview of the available computer models for the simulation of SWI is given by Sorek and Pinder (1999).

The direct threats of invasive saline water on groundwater led the geo-environmental and water resources engineers throughout the world to discover the some practical solutions to Control SWI. These include reduction of pumping rates, relocation of pumping wells, use of subsurface physical barriers, natural and artificial recharge, use a line of injection wells (pressure barrier) along the coast, pumping of saline water (abstraction barrier) along the seacoast and combination techniques ( Banks and Richter (1953), Bruington (1972), Todd (1974), Van Dam (1999) and Sherif and Hamza (2001)). In order to assess the efficiencies of these methods the simulation model should be linked with the optimization tools. In comparison with traditional optimization methods, the recent developed Evolutionary Algorithms (EAs) can efficiently accomplish this goal by addressing the optimal solutions of the nonlinear and complex optimization problems in a wide search space of design variables. The majority of previous research on optimal management of SWI considered the simplified sharp interface theory, integrated with optimization tools. However, Qahman et al., (2005; 2009), Bray and Yeh (2008), Dhar and Datta (2009), Lin et al. (2009), Kourakos and Mantoglou (2011) and Javadi et al. (2012) integrate the variable-density models directly with the optimization tools to evaluate different SWI management approaches.

The numerical simulation of the variable density hydrogeological system (e.g the coastal aquifer under saltwater intrusion) suffers from computational inefficiency. Beside this the multi-running of the simulation during the optimization process emphasis this computational complexity. For instance, Dhar and Datta (2009) reported a 30-day run time for S/O of a typical and small 3D aquifer which is simulated under saturated condition. Generally, this problem force the group of the researchers (e.g. Das and Datta (1999a; 1999b), Rao et al. (2004), Bhattacharjya and Datta (2005; 2009), (Dhar and Datta, 2009), Sreekanth and Datta (2010; 2011a; 2011b) and Kourakos and Mantoglou (2009; 2013)) to think about application 
of intelligent techniques to work as an alternative for the simulation model to alleviate this data processing burden. They used Artificial neural network (ANN), Genetic Programming (GP) and Modular Neural Network (MNN) as the common surrogate models. The main idea behind these metamodels is that they learn from experience and extract various discriminants, each appropriate for its purpose.

In this paper a new surrogate model called Evolutionary Polynomial Regression (EPR) is presented to work as alternative for simulation of the SWI in 2D conceptual model. By training the EPR models on the results of FE simulation model their potentials in predication the response of the aquifer system are first illustrated. And in second study the EPR models have been integrated with the multi-objective optimization algorithm to assess different management scenarios to control SWI. The results of the later scheme S/O are compared with those identified by direct integration of the numerical simulation model with the optimization tool. In terms of the management scenarios the work present three different management methods to control SWI in unconfined aquifers. In addition, by focusing on the treated wastewater (TWW) as a more economic source of water for recharging, the new combined methodology called ADRTWW is proposed to control the SWI. The model consist of deep abstraction of saline water near the coast followed by Desalination this water to a potable level and Recharging the aquifer with external source of water such as Treated Waste Water (ADRTWW). The ponded TWW is allowed to percolate through the unsaturated zone to the underlying aquifer using a subsurface recharge basin. The efficiency of this scenario is assessed in terms of minimization the both total management cost and the total mass of salt in the aquifer using the S/O process. The results are compared with other two different scenarios of the control. The optimal depths and locations of abstraction barrier are also addressed by these processes. Finally the study attempts to evaluate the effects of different recovery ratios of desalination plant and cost impacts of supplying recharge water from different external sources on the cost-efficiency of the proposed scenario.

\section{Evolutionary Polynomial Regression(EPR)}

In traditional data driven techniques such as GP and neural networks an output $\mathbf{Y}$ of a physical system can be presented as $\mathrm{m}$ dimensional function $F$ of a set of m-numbers of inputs $\mathbf{X}$ and a set of parameters $\boldsymbol{\theta}$.

$$
\mathrm{Y}=F(\mathrm{X}, \boldsymbol{\theta})
$$

GP generated a population of expressions for $F$ coded in tree structures of variable size, and performs a global search of the best-fit expression for $F$. However, the parameters values (vector $\boldsymbol{\theta}$ ) are generated as non-adjustable constants and do not necessarily represent optimal values as in numerical regression methods. Such feature negatively affects and in consequence a good structure of $F$ can be missed in the process. On the other hand, the ANN aims to map $F$ rather than to find a feasible structure for it. Furthermore, the large complexity of the network structure is the main disadvantage of the neural network-based models. This network is representing the knowledge in terms of a weight matrix that is not accessible to the user (Rezania et al., 2008). 
By looking on these drawbacks of GP and NNs, Giustolisi and Savic (2006) introduced new approach called Evolutionary Polynomial Regression (EPR) as a hybrid data driven method that integrates the best features of conventional numerical regression techniques with the genetic programming and symbolic regression techniques. Therefore, in EPR technique there is possibility of to view the structure of the models in the form of polynomial mathematical expressions, the feature which is not available in other data driven methods such as ANN. A typical formulation of the EPR expression is given as:

$$
\mathbf{Y}=\sum_{j=1}^{m} F\left(\mathbf{X}, f(\mathbf{X}), a_{j}\right)+a_{0}
$$

where $\mathrm{Y}$ is the estimated output of the system; $a_{j}$ is a constant value; $F$ is a function constructed by the process; $\mathbf{X}$ is the matrix of input variables; $f$ is a function defined by the user; and $m$ is the number of terms of the expression excluding bias $a_{0}$. In this algorithm and to determine the symbolic model, first the functional structure of the model represented by $F\left(\mathbf{X}, f(\mathbf{X}), a_{j}\right)$ is identified and then the constant coefficients and exponents (parameter estimation) would be calculated. In first stage the feasible structure of the model is captured using the GA and in the second stage the least square method is used to find the appropriate constants $a_{j}$ for those structures. Before starting the EPR process, some of the EPR parameters must be adjusted to control the building elements of the structure of $F$. These parameters can control the optimisation techniques (i.e. single-objective or multi-objective), number of terms of the mathematical expressions, range of exponents, EPR structures and the type of the functions used to construct the EPR models. By this The EPR start to seek the best symbolic model(s) of the system being studied using optimisation process implemented by GA .

The complexity (including number of terms, number of inputs) and fitness of EPR expressions are the main objective functions of this optimisation process. EPR can work both in single as well as multi-objective configurations. In single-objective the model optimised to control the fitness of the models without allowing unnecessary complexities enter in the models. In the case of multi-objective strategy two or three objective functions are introduced in which one of them will control the fitness of the models, while at least one objective function controls the complexity of the models.

The accuracy (the fitness function) of every proposed model for each particular application at each stage is evaluated based on the coefficient of determination (COD) which is defined as:

$$
C O D=1-\frac{\sum_{N}\left(\mathrm{Y}_{a}-\mathrm{Y}_{p}\right)^{2}}{\sum_{N}\left(\mathbf{Y}_{a}-\frac{1}{N} \sum_{N} \mathbf{Y}_{a}\right)^{2}}
$$

where $\mathrm{Y}_{a}$ is the actual output value; $\mathrm{Y}_{p}$ is the EPR predicted value and $N$ is the number of data on which $C O D$ is computed. If the model fitness is not acceptable or the other 
termination criteria (in terms of maximum number of generations and maximum number of terms) are not satisfied, the current model goes through another evolution in order to obtain a new model. In consequence more than one model is provided by EPR for a complex phenomenon ranked based on their COD values. In recent decade, the algorithm has been applied in different fields of the civil engineering by group of researchers (Giustolisi et al. (2007); Giustolisi et al. (2008); Ahangar-Asr et al. (2010); Rezania et al. (2011); AhangarAsr et al. (2012); Faramarzi et al. (2013); Faramarzi et al. (2014)). Detailed explanation of the EPR can be found in Giustolisi and Savic (2006) and the mentioned references.

\section{Model description}

A 2D descriptive model of unconfined aquifer with dimensions $200 * 100 \mathrm{~m}$ is considered which is the relatively shallow aquifer. The system simulated using finite element based model called SUTRA (Saturated-Unsaturated TRAansport flow and solute transport model). SUTRA is developed by (Voss, 1984) and it uses a hybridization of finite element and integrated finite difference methods to solve the saturated/unsaturated partial and dependent flow and transport mass balance equations in 2D/3D systems. The aquifer discretised with 2000 elements and 2091 nodes. It was divided vertically in two layers, an unsaturated layer overlying the bottom saturated layer. This unsaturated flow system is simulated with a fine spatial and temporal discretization to limit the instability and oscillatory results of calculated pressure and saturation values which may changes sharply during wetting events (Voss and Provost, 2010). The hydrostatic water head $31 \mathrm{~m}$ and $30 \mathrm{~m}$ were assigned to the left and right sides of the domain respectively to represent the freshwater and seawater pressure boundaries of the simulated aquifer respectively. The natural initial values of pressure within the domain are obtained through an extra steady stare simulation with the mentioned boundary conditions of the aquifer. Figure 1 illustrates the natural steady state distribution of concentration through the system presented by $10 \%, 20 \%$ and $50 \%$ iso-concentration contour lines. The main input data for the simulation model are given in Table 1. Simulation of the unsaturated layer requires the soil water characteristic curve (SWCC) which presents the relationship between capillary pressure and fluid saturation of soil. In this study the Van Genuchten (1980) model is used to simulate the transient aspects of unsaturated flow in the top layer of aquifer. The residual saturation at immobile state of flow $S_{\text {res }}=0.23$ and fitting parameters $\alpha=2 * 10^{-4}$ $\left(\mathrm{m} . \mathrm{s}^{2}\right) / \mathrm{kg}, \mathrm{n}=1.3$ are the three parameters were considered in Van Genuchten function.

\section{First study: prediction of the locations of the saline wedge toes}

The variations of salinity to different patterns of the abstraction in the system, illustrated in preceding section, are predicated by EPR as the response of the system under SWI impacts. For this purpose the EPR is trained and tested on the set of the inputs and corresponding target output. Generally, the 50\% iso-concentration line has been used by enormous researchers in order to show the levels of the risk associated by SWI. The inland progressive of the toe location for this isocholar $\left(\mathrm{T}_{50}\right)$ is highlighted in literature to represent the intrusive saltwater wedge. The other feature of the SWI which also has been focused in group of the researches is the thickness of dispersive zone $\left(\mathrm{T}_{\mathrm{d}}\right)$. In practice, concentrations of total 
dissolved solids ranging from about 1,000 to $35,000 \mathrm{mg} / \mathrm{l}$ and of chloride ranging from about 250 to $19,000 \mathrm{mg} / \mathrm{l}$ are common indicators of this mixing zone (Patel and Shah, 2008). The mixing zone is commonly characterized by zone occupied by the $10 \%$ and $90 \%$ salinity ischolars (Price and Herman (1991); Wicks and Herman (1995) and Ataie-Ashtiani et al. (1999)).Therefore, the $\mathrm{T}_{\mathrm{d}}$ can be obtained approximately by identification the $\mathrm{T}_{10}$ and $\mathrm{T}_{90}$ which are the location of toes for 10\% and 90\% ischolars respectively (Error! Reference source not found.).

Correspondingly, in this work and by following the EPR approaches three different equations representing the relation of each mentioned toes $\left(\mathrm{T}_{10}, \mathrm{~T}_{50}\right.$ and $\left.\mathrm{T}_{90}\right)$ with the available pumping input parameters are developed.

Table 1: The parameters used in descriptive problem.

\begin{tabular}{|c|c|c|}
\hline$\overline{\mathrm{Dm}}$ & : coefficient of water molecular diffusion $\left[\mathrm{m}^{2} / \mathrm{s}\right]$ & $1.0 * 10^{-9}$ \\
\hline $\mathrm{t}$ & : thickness of model $[\mathrm{m}]$ & 1.0 \\
\hline$\partial \rho / \partial \mathrm{C}$ & $\begin{array}{l}\text { : change of fluid density with concentration } \\
{\left[\mathrm{kg}^{2} \text { (seawater) } / \mathrm{kg} \text { (dissolved solids). } \mathrm{m}^{3}\right]}\end{array}$ & 700 \\
\hline g & : gravitational acceleration $\left[\mathrm{m} / \mathrm{s}^{2}\right]$ & 9.8 \\
\hline Csea & : solute mass fraction of seawater $[\mathrm{kg}$ (dissolved solids) $/ \mathrm{kg}$ (seawater)] & 0.0357 \\
\hline $\rho$ sea & : density of sea water $\left[\mathrm{kg} / \mathrm{m}^{3}\right]$ & 1025 \\
\hline рo & : density of fresh water $\left[\mathrm{kg} / \mathrm{m}^{3}\right]$ & 1000 \\
\hline$\mu$ & : fluid viscosity $[\mathrm{kg} /(\mathrm{m} . \mathrm{s})]$ & 0.001 \\
\hline$\alpha \mathrm{L}$ & : transverse and longitudinal dispersivity $[\mathrm{m}]$ & 5.0 \\
\hline$\alpha \mathrm{T}$ & : transverse dispersivity $[\mathrm{m}]$ & 0.5 \\
\hline \multirow{2}{*}{$\mathrm{k}$} & : permeability of saturated zone $\left[\mathrm{m}^{2}\right]$ & $5.0 * 10^{-11}$ \\
\hline & : permeability of unsaturated zone $\left[\mathrm{m}^{2}\right]$ & $2.5 * 10^{-13}$ \\
\hline \multirow{2}{*}{$\varepsilon$} & : porosity of saturated zone[ dimensionless ] & 0.25 \\
\hline & : porosity of unsaturated zone[ dimensionless ] & 0.3 \\
\hline
\end{tabular}

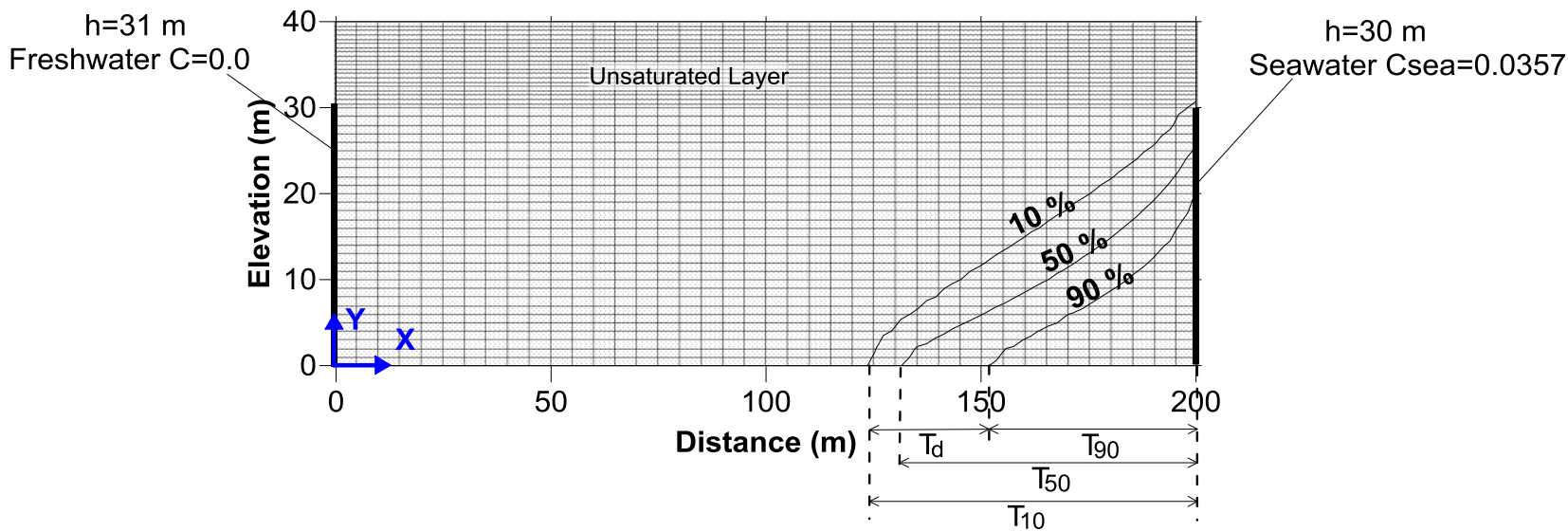

Figure 1: Boundary conditions and the steady state distribution of salinity of the system

The input parameters considered to train and test the EPR are the coordinate (XA,YA) and the pumping rates (QA) of abstraction well (A single node is used to represent the pumping well). These parameters with the size of 1000 are generated randomly with the uniform 
probability distribution. 800 of these database are used for training the EPR and remain 200 data are used for validation (testing) which are not seen by EPR. The range of generated data are $0.0<\mathrm{XA}(\mathrm{m})<200.0 ; 0.0<\mathrm{YA}(\mathrm{m})<30.0$ and $0.0<\mathrm{QA}\left(\mathrm{m}^{3} /\right.$ day $)<52.0$.

once the input field generated, the calculation process of the outputs $\mathrm{T}_{10}, \mathrm{~T}_{50}$ and $\mathrm{T}_{90}$ corresponding to each set of these input data is started by multi running of the SUTRA to represent the response of the system. The SUTRA code has been modified to handle these toe locations. In order to start the EPR process the some user parameters have been adjusted: 20 as the number of terms, the range of exponents was limited to [-2 2] and also multi-objective strategy was used to develop the EPR functions.

\subsection{Developed EPR models representing the toe locations}

By implementing the EPR principles three different polynomial functions are developed to represent different seawater wedge toes. Each of these proposed models is trained using the training data and tested using the testing data. Among developed models, the shortest model with the least possible number of terms and with the highest value of COD was selected to represent the toes $\left(\mathrm{T}_{10}, \mathrm{~T} 50\right.$ and $\left.\mathrm{T}_{90}\right)$. The results of EPR including the obtained equations are presented in the Eqs. (4,5, and 6). Also the comparison between the predicated values by these metamodels with the results simulated by FE are illustrated in Figure 2 for both training and validation stages. The COD values for training and validation sets for each EPR model are also illustrated on these set of figures. The results indicate very good correlation between the predictions of the EPR model and the FE model for both modelling and validation datasets.

$$
\begin{aligned}
T_{10}= & -161.324+61.137 X A^{0.5}-4.689 X A+\left(4.748 * 10^{-3}\right) X A^{2} \\
& +\left(4.468 * 10^{-4}\right) Y A^{0.5} X A^{2}+40.208 Q A^{0.5}-6.421 Q A X A^{-1} \\
& -\left(61.132 * 10^{-2}\right) X A^{0.5} Q A+\left(3.546 * 10^{-4}\right) X A Q A^{2} \\
T_{50}= & -203.399-393.257 X A^{-1}+67.483 X A^{0.5}-5.051 X A+\left(5.113^{*} 10^{-3}\right) X A^{2} \\
& +\left(4.533 * 10^{-4}\right) Y A^{0.5} X A^{2}+22973.397 X A^{-2} Q A^{-1}+45.009 Q A^{0.5} \\
& -\left(68.817 * 10^{-2}\right) X A^{0.5} Q A+\left(4.032 * 10^{-4}\right) X A Q A^{2} \\
T_{90}= & -296.927+81.257 X A^{0.5}-5.642 X A+\left(6.159 * 10^{-3}\right) X A^{2} \\
& +\left(5.65{ }^{*} 10^{-5}\right) Y A X A^{2}+25302.076 X A^{-2} Q A^{-1}+32.534 Q A^{0.5} \\
& -\left(3.583 * 10^{-2}\right) X A Q A-\left(8.682 * 10^{-3}\right) Q A^{2}+\left(1.824 * 10^{-6}\right) X A^{2} Q A^{2}
\end{aligned}
$$



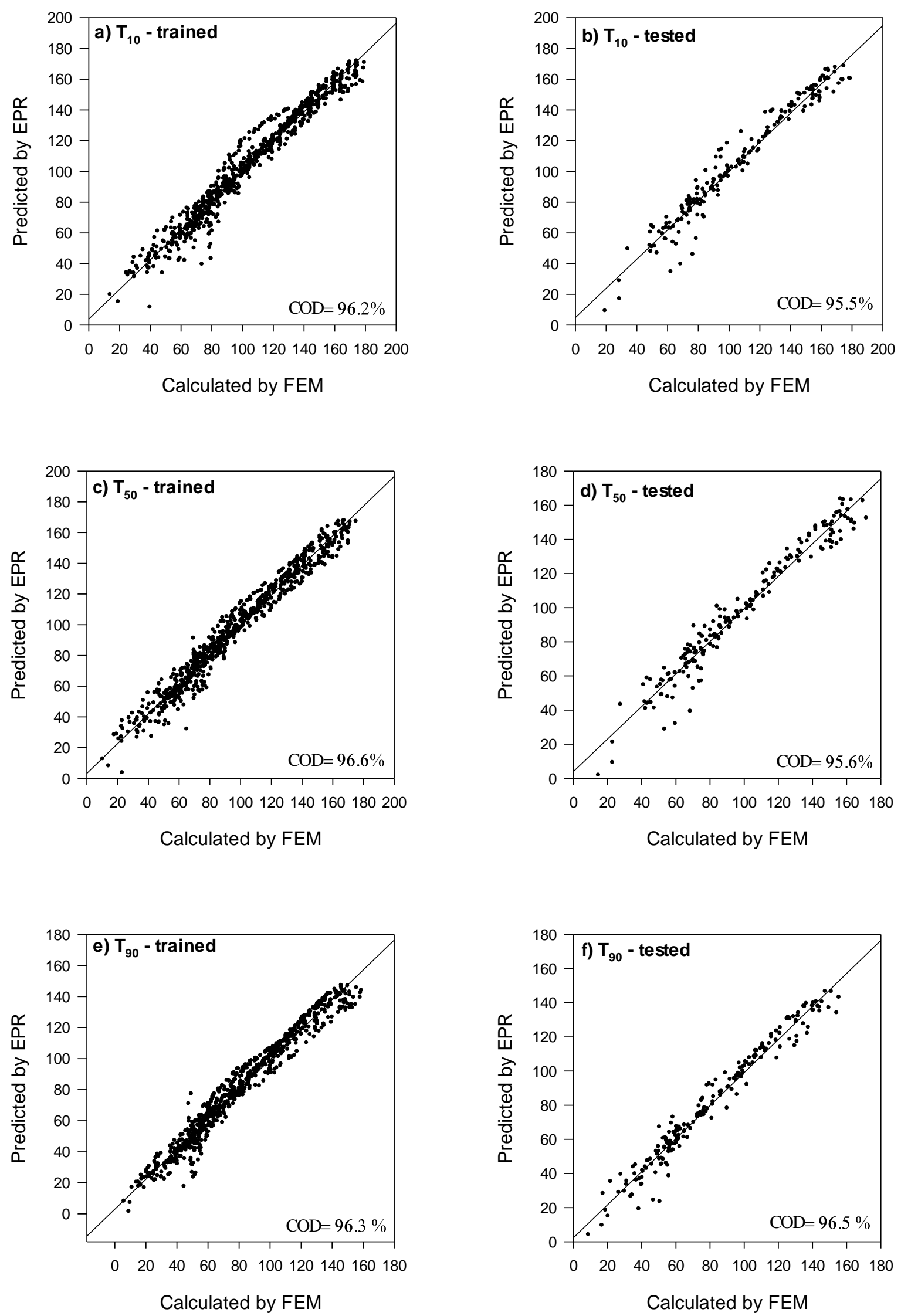

Figure 2: Comparison of the EPR-predicted results of $\mathrm{T}_{10}, \mathrm{~T}_{50}$ and $\mathrm{T}_{90}$ with measured their results calculated by FE for both trained and tested databases. 


\subsection{Verification of the de veloped models}

In order to verify the results of the developed EPR models, in particular study the effect of different rates of pumping on the overall progress of these toes have been simulated using the both numerical and developed EPR models. For this purpose the location of the pumping well is fixed at the coordinates $(\mathrm{XA}=80.0 \mathrm{~m}, \mathrm{YA}=10.0 \mathrm{~m})$ to have a depth equal to $30.0 \mathrm{~m}$ below ground surface. Following the increasing pattern the well subjected to different rates of the abstractions in the range of $0.0<\mathrm{QA}\left(\mathrm{m}^{3} /\right.$ day $)<52.0$.

The results obtained from this parametric study are also in good agreements with the FE results as shown in Figure 3. The impossibility in training the EPR for each and every pattern within the problem domain and also the limitation to choose the developed models with reasonable mathematical structure are the main causes for the infeasibility of the results in some points. The results obtained from these metamodels are summarized in Figure 3(d). The difference between the curves located in top and bottom ( $\mathrm{T}_{10}$ and $\mathrm{T}_{90}$ respectively) show the variation trend in thickness of the dispersive zone $\left(\mathrm{T}_{\mathrm{d}}\right)$ with gradually increasing pumping rate.

Although availability of the large field database to obtain the response of the aquifer is not reasonable in practice; the rationality behind the demonstrated study was just to show the potentials of the EPR to predict of the nonlinear properties of the hydrological system. The importance of such potentials emerges during the S/O process by saving the computational burden that have been discussed in the following sections.
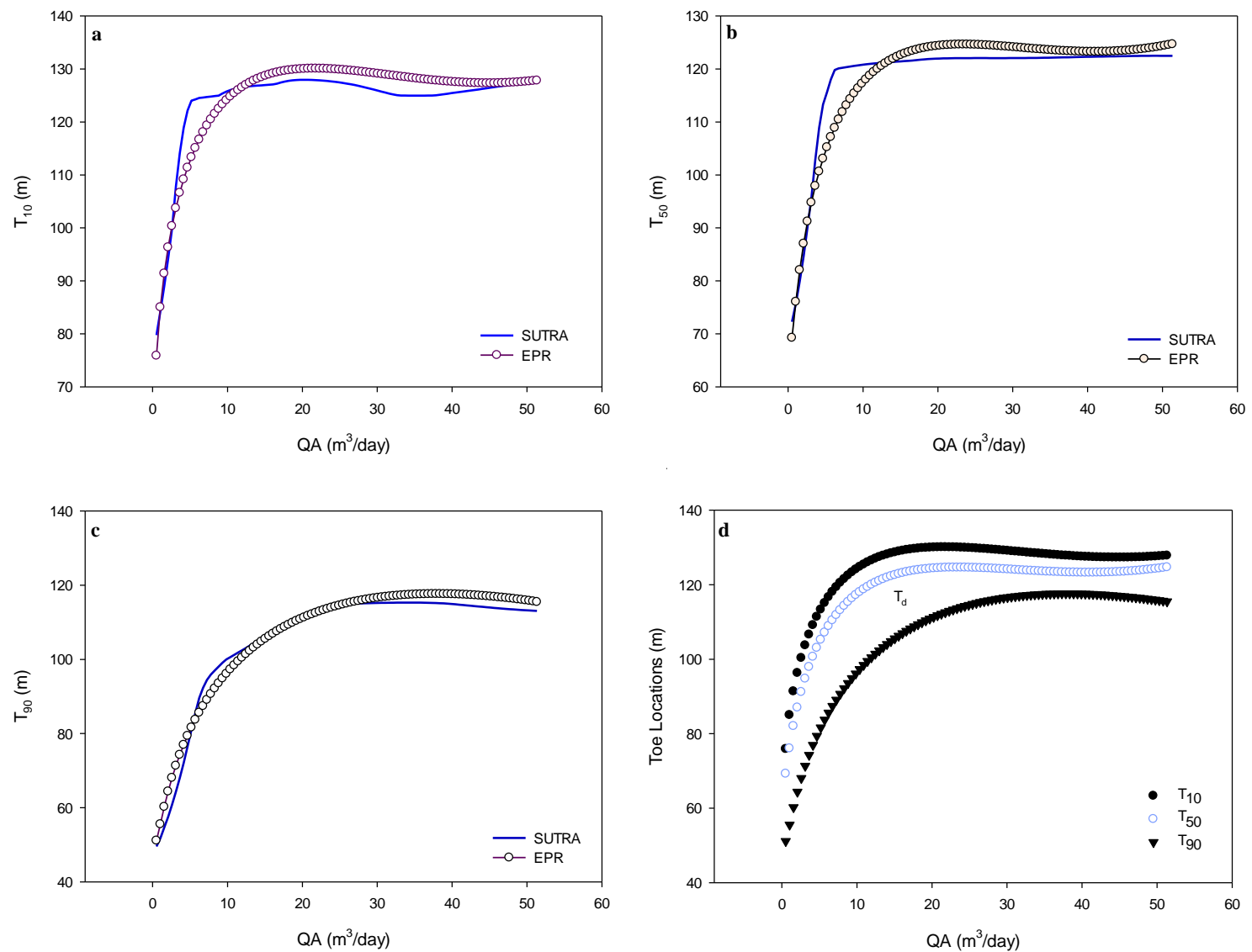

Figure 3: Calculated values of a) $\left.\mathrm{T}_{10}, \mathrm{~b}\right) \mathrm{T}_{50}$ and c) $\mathrm{T}_{90}$ by EPR and FE; d) Summary of these predicted values by EPR models. 


\section{Second study: management of the SWI (Simulation-Optimization)}

In order to control the SWI the aquifer is subjected to different combined (involve the both recharge and abstraction) management scenarios. The study is carried out on the same 2D system. The all parameter and boundary conditions of the conceptual aquifer are kept same as before. However to simulate a plan for future demand, a production well pumping fresh water with constant rate of $26 \mathrm{~m}^{3} /$ day at a location $40 \mathrm{~m}$ from the inland boundary and depth of 30 $\mathrm{m}$ was incorporated in the model. Figure 4 shows the location of this production well and the resulted steady state distributions of salinity in the aquifer before and after the current pumping rate. The 50\% iso-concentration lines are used to represent the levels of the salinity. The system reached a steady state after 15000 time steps, with time step of 0.05 days. The total calculated mass of solute in the aquifer would be raised from 27 tons prior the pumping to 98 tons after pumping. The results in Figure 4 show that the aquifer and the planned production well are threatened by SWI. In order to alleviate this problem, a management action is required to be taken to comply with the planned demands for water while protecting the aquifer against SWI.

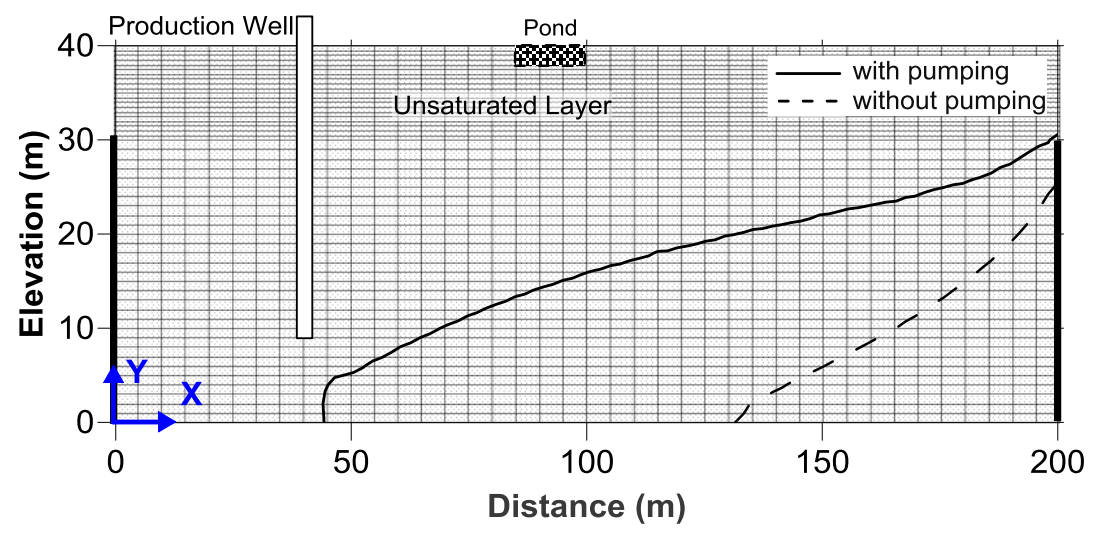

Figure 4: Pre and post-pumping distribution of salinity ( 0.5 isochlors).

Three different management scenarios considered to hydraulically restrict the negative aspects of the saline intrusion wedge during pumping of freshwater from the production well. These scenarios are i) Abstraction of saline water followed by Desalination and Recharging the aquifer with the same desalinated water (ADR), ii) Abstraction of saline water followed by Desalination and Recharging the aquifer with Treated Waste Water (ADRTWW) and iii) Abstraction of saline water and Disposal to sea followed by Recharging the aquifer with Treated Waste Water (ADsRTWW). In these scenarios the recharge is implemented by artificial subsurface pond to allow collected water to infiltrate into the aquifer. The recharge pond has $15.0 \mathrm{~m}$ long and $2.0 \mathrm{~m}$ deep to replenish $2.0 \mathrm{~m}$ constant head of water in aquifer. The typical form of the pond is also illustrated in Figure 5. Desalinated water with total dissolved solids (TDS) of $250 \mathrm{mg} / \mathrm{l}\left(0.00025 \mathrm{~kg}_{\mathrm{s}} / \mathrm{kg}_{\mathrm{f}}\right)$ and TWW with $1300 \mathrm{mg} / \mathrm{l}(0.0013$ $\mathrm{kg}_{\mathrm{s}} / \mathrm{kg}_{\mathrm{f}}$ ) are the two different type of water that used to feed the aquifer in these scenarios. The average rate of recharge directly under pond is $0.35 \mathrm{~m} /$ day $\left(5.184 \mathrm{~m}^{3} /\right.$ day $)$ which is calculated by SUTRA. 


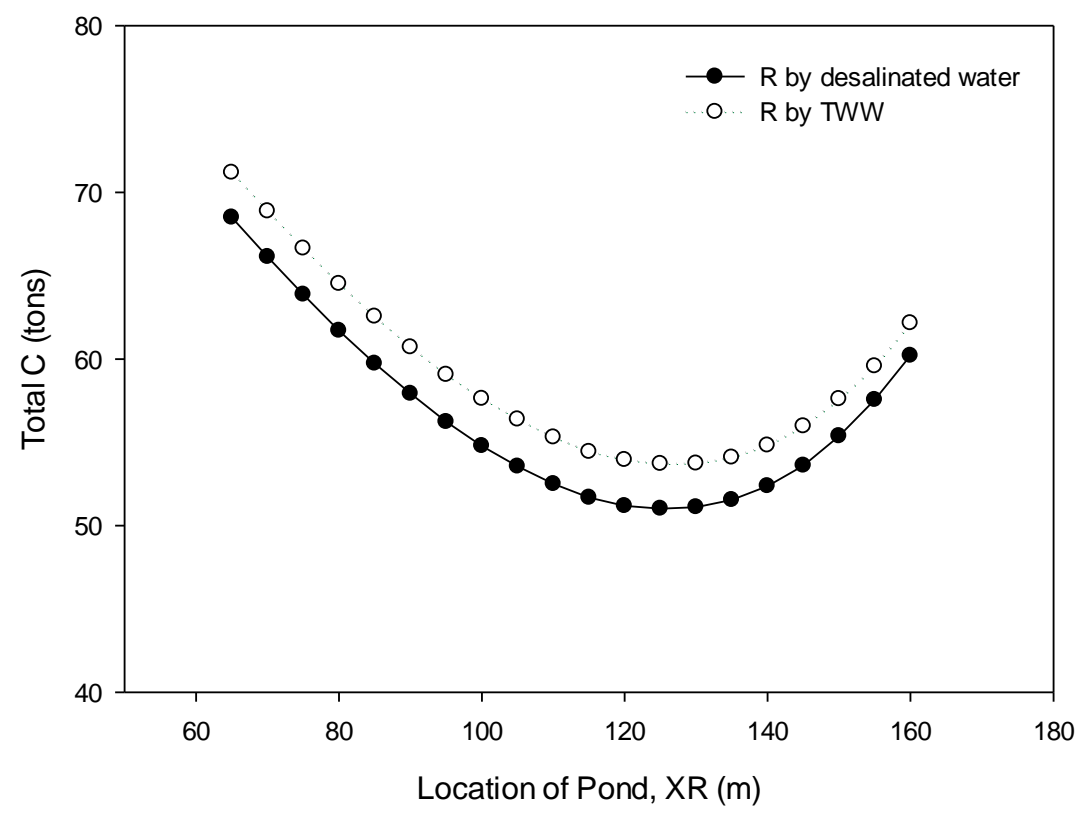

Figure 5: Variations of total concentration in the system with the pond location

The ADR was proposed by Javadi et al. (2012) as an effective and economic method for controlling SWI. ADR is based on continuous abstraction of brackish water near the coast, desalination of the abstracted brackish water (e.g., using reverse osmosis) and using the excess of the desalinated water as a source of artificial recharge while the rest of the desalinated water is used to meet part of the demand for water (Javadi et al., 2012). A new methodology ADRTWW is developed in the present study as the second scenario where the abstracted water is desalinated and used, while an external source of TWW is used for recharge. Finally in the third scenario the all abstracted water is directly disposed to sea without any treatment and the external TWW is used as the source of recharge.

In addition and in order to guarantee the maximum efficiency from this recharge system the effective location of the pond (XR) is readily obtained through parametric study by variation of pond location along the length of the domain simultaneously with measuring the total solute mass in system. Based on the quality of used recharge water two different schemes are considered. In first scheme the aquifer is recharged by the excess of desalinated water, while in second one it is recharged by treated wastewater (TWW). The results show that the location of pond (XR) between $100.0 \mathrm{~m}$ and $135.0 \mathrm{~m}$ from the shoreline is the effective location for designing the pond to get a more environmentally friendly result. Therefore, the location of the recharge system is fixed at $\mathrm{XR}=115.0 \mathrm{~m}$ (or $70.0 \mathrm{~m}$ from the shoreline by considering the width of the pond) in all three management strategies. The efficiency of these scenarios under the mentioned circumstances in terms of the management cost and salinity control is investigated in two different schemes: by integrating the numerical model and surrogate model (EPR) with the multi objective optimization tool (Non-dominated Sorting Genetic Algorithm (NSGAII) in this study). 


\subsection{FE-GA}

In the follow-up phase of the study and by direct linking of the numerical model to NSGAII the efficiency of the developed combined management scenarios are assessed to control the lateral inland intrusion of saline water in the shallow aquifer under the continuous pumping from production well.

NSGAII is one of the widely-used multi-objective evolutionary algorithms which was proposed by Deb et al. (2002a). During the S/O process, the NSGAII repeatedly calls SUTRA to compute state variables (pressures and concentrations) in response to each set of generated design variables. After computing the objective function and evaluating its fitness, the processes of selection, crossover, and mutation are performed in NSGA-II to update the values of decision variables and select the best solutions from mating pool of parent and offspring populations. NSGA-II organizes the members of the population into nondominated fronts after each generation, based on the conflicting objectives of optimization. If in the final stage there are more individuals in the nondominated front than available space, the crowded distance-based niching strategy is used to choose which individuals of that front are entered into the next population (Deb et al., 2002b). The new values of decision variables are then returned to SUTRA and the process is repeated until it satisfies optimal criteria or it reaches the maximum generation and finally it captures the Pareto of optimal solutions for the problem.

Two conflicting objectives are considered in the $S / O$ process. The first one is the minimization of total mass of salt in the aquifer $\left(f_{1}\right)$ and the second one is minimization of the costs of construction and operation of the management process $\left(f_{2}\right)$. Based on available parameters in each scenario, the objective functions and the set of used constraints are expressed mathematically as follows:

$$
\min f_{1}=\sum_{i=1}^{N} C_{i} v_{i}
$$

$1-\mathrm{ADR}$

$$
\begin{aligned}
\min f_{2}= & Q R * C R * \Delta t+D A * C D+Q A *(C A+C T) * \Delta t \\
& -(r * Q A-Q R) * M P T * \Delta t+C P+C P M
\end{aligned}
$$

\section{2-ADRTWW}

$$
\begin{aligned}
\min f_{2}= & Q R *(C R+M P T W) * \Delta t+D A * C D+Q A *(C A+C T) * \Delta t \\
& -r * Q A * M P T * \Delta t+C P+C P M
\end{aligned}
$$

\section{3-ADsRTWW}

$$
\begin{aligned}
\min f_{2}= & Q R *(C R+M P T W) * \Delta t+D A * C D+Q A * C A * \Delta t \\
& +C P+C P M
\end{aligned}
$$


Subject to:

$$
\begin{aligned}
& 0.0<Q A\left(m^{3} / \text { day }\right)<52.0 \\
& 0.0<X A(m)<200.0 \\
& 0.0<Y A(m)<30.0 \\
& \text { Total } C<27.0 \text { tons }
\end{aligned}
$$

(total $\mathrm{C}$ for no management model prior the pumping from the production well=27 tons)

where $f_{1}$ and $f_{2}$ are objective functions, $\mathrm{N}$ is total number of nodes in the domain, $\mathrm{C}_{\mathrm{i}}$ is the solute concentration at node $\mathrm{i}, \mathrm{v}_{\mathrm{i}}$ is cell volume at node $\mathrm{i}$, QA is abstraction rate $\left(\mathrm{m}^{3} /\right.$ day), QR is recharge rate $\left(\mathrm{m}^{3} /\right.$ day), $\mathrm{XR}$ is horizontal coordinate of recharge pond, XA and YA are the spatial coordinates of abstraction well. DA is depth of abstraction well (m). CR, CA, CT and $\mathrm{CD}$ are costs of artificial recharge by pond $\left(\$ / \mathrm{m}^{3}\right)$, abstraction $\left(\$ / \mathrm{m}^{3}\right)$, treatment $\left(\$ / \mathrm{m}^{3}\right)$ and installation/drilling of well $(\$ / \mathrm{m})$ respectively. MPT $\left(\$ / \mathrm{m}^{3}\right)$ and MPTW $\left(\$ / \mathrm{m}^{3}\right)$ are market prices of desalinated water and TWW respectively. CP is the cost of construction of pond (\$) which includes the cost of excavation and soil removal for a $2.0 \mathrm{~m}$ deep pond. CPM is annual cost of maintenance and cleaning of pond (\$), $\Delta \mathrm{t}$ is the duration of application of the management strategy and $r$ is the recovery ratio of desalination plant.

The SUTRA code is modified to calculate total mass of salt in the aquifer $\left(f_{1}\right)$ by accumulative multiplication of the total solute concentration at each node by the volume of each FE cell at the corresponding node. The design variables considered in the S/O model of all these scenarios are summarized in Figure 6. The total cost is calculated based on the unit costs of installation/drilling of well (\$200 per unit depth), abstraction $\left(\$ 0.42 / \mathrm{m}^{3}\right)$, recharge $\left(\$ 0.12 / \mathrm{m}^{3}\right)$, desalination (treatment) $\left(\$ 0.6 / \mathrm{m}^{3}\right)$, market price of desalinated water $\left(\$ 1.5 / \mathrm{m}^{3}\right)$, market price of TWW $\left(\$ 0.25 / \mathrm{m}^{3}\right)$ and total cost of construction of a pond with dimensions $15.0 \mathrm{~m} \times 2.0 \mathrm{~m} \times 1.0 \mathrm{~m}(\$ 350)$. The cost of maintenance of the pond is assumed to be $10 \%$ of its construction (Abazza, 2012; Asano and Bahri, 2010; Chen et al., 2003; Isaka, 2012; Javadi et al., 2012). Depending on the feed water quality, typical value of the recovery ratio varies from 50 to 80 percent for brackish water (and 20 to 40 percent for seawater) using standard reverse osmosis plants (Singh, 2013). Therefore in this study a recovery ratio of $60 \%$ is assumed for desalination of brackish water.

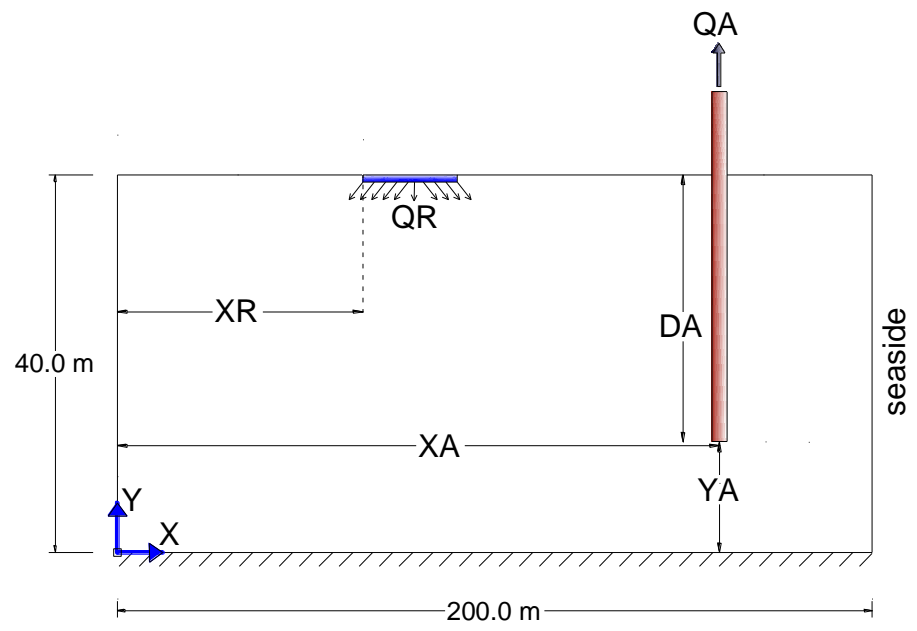

Figure 6: Schematic sketch for the variables used in the management scenarios. 
Figure 7 provides the results of trade-off between the two objectives in all three management strategies. All scenarios show their capability to optimally control SWI. The results indicate that the second scenario ADRTWW shows significantly greater efficiency in terms of minimizing the total cost and salinity concentration than the other strategies. This is because ADRTWW offers the whole of the abstracted and desalinated water as additional source of water supply. Although, this TWW contains a greater salinity than desalinated water, it helps to retard the saline water by increasing the seaward gradient of water heads. Consequently, the ADRTWW management methodology is recommended to control the SWI trend in relatively shallow unconfined aquifer systems. On these trade-off curves, simultaneously the corresponding effective coordinate of the barrier well and its optimal pumping rates to maintain the water quality (control the SWI) are also addressed by the S/O. It can be noted that deep location of barrier well near the shoreline are the common abstraction pattern reported by $\mathrm{S} / \mathrm{O}$. In other word, the illustrated optimal solutions along each Pareto frontiers are originated from pumping of water at these effective locations of the abstraction well. From physical point of view, the production well causes the saltwater wedge to move towards land and to compensate this problem the barrier well should be located at the zone with highest salinity inside the saltwater wedge to increase the efficiency of the management process. Also, the violation of the subjective constraint formulated in Equation 14 play an important role in these results were at such locations its violation decreases. Consequently, the corresponding optimal solutions with the best performance along the trade-off curves should be apparently developed from such a set of pumping locations. A various range of pumping rates from the barrier well has been reported in these scenarios as optimal for the corresponding optimal individuals of each trade-off curves.

In the framework of the FE-GA, each calls of the simulation model by population based optimization tool (GA) for evaluating a candidate solution, a huge computational burden is imposed on management model to obtain the global optimal solutions. To solve this problem the numerical simulation model is replaced by EPR based model in S/O process.

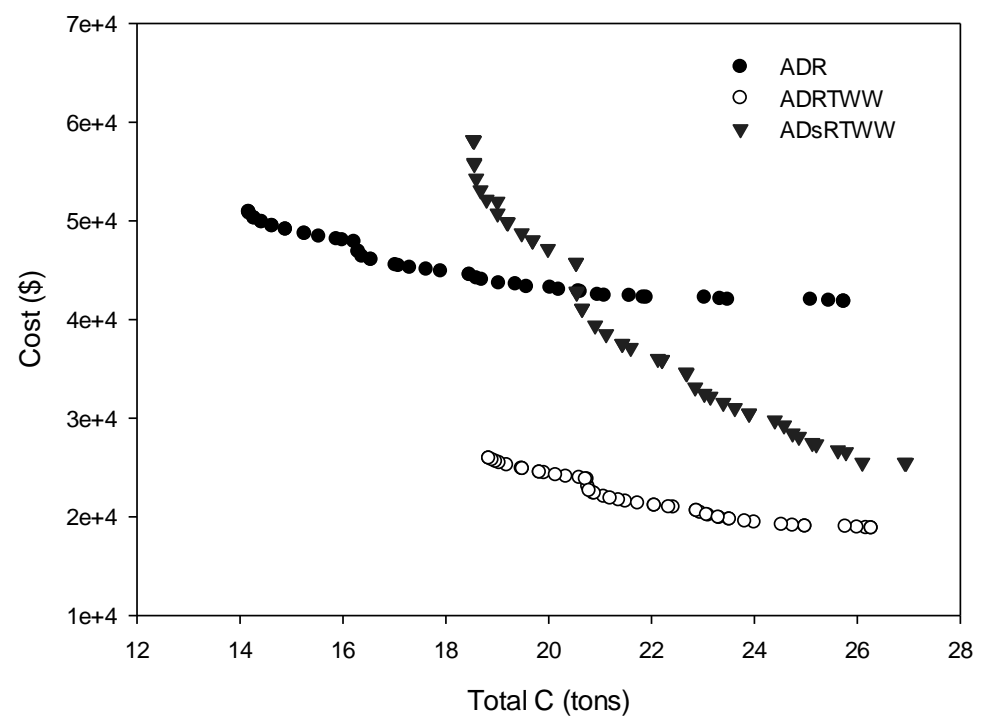

Figure 7: Pareto frontiers of all management scenarios obtained by FE-GA. 


\subsection{EPR-GA}

The good advances of the EPR models in first study (see section 4) to predict the FE results of the SWI simulation and also the extensive computational complexity of the direct linking of the simulation model to GA motivating the current study to use EPR as alternatives to deal with the NSGAII in second scheme of the S/O framework. For this purpose, the EPR was trained and tested in each of the three scenarios to find the best functions describing the response of the aquifer system under different pumping pattern. The numerical simulation model (SUTRA) was used to determine these aquifer responses.

The input parameters considered are XA, YA and QA of the abstraction well. The results of the FE-GA indicated that the deep abstraction of water near the coast are the optimal location approaching to the maximum efficiency therefore in EPR-GA the locations of the pump limited to the right hand side of the recharge pond to save the time. Thus, the input data are generated in the following ranges: $135.0<\mathrm{XA}(\mathrm{m})<200.0 ; \quad 0.0<\mathrm{YA}(\mathrm{m})<30.0$ and $0.0<\mathrm{QA}\left(\mathrm{m}^{3} /\right.$ day $)<52.0$.

These parameters with the size of 500 are generated randomly with the uniform probability distribution. Then, by multi running of the SUTRA the output (total mass of solute, $\mathrm{f}_{1}$ ) corresponding to each set of these data are calculated as the response of the system in each control scenario. With this set of the inputs/outputs the required database for training and validation of the EPR models has been provided. In each scenario 400 of these data are used for training and the remaining 100 data are kept unseen during the model development process and used for validation of the developed model. The number of expected terms adjusted to 20, the range of exponents was limited to [-2 2] and finally the type of optimization was screened as multi-objective strategy in the user interface of the EPR algorithm in order to develop the EPR functions.

Although, the EPR aims finding appropriate structure of the first objective function only the fed input data will be used concurrently in evaluating the second cost function $\left(f_{2}\right)$ as well. It is worth mention that the ADRTWW and ADsRTWW have the same arrangements in terms of the hydraulic barriers (recharge and abstraction) and therefore the same set of generated database and the same developed model have been used for both of them and they are different only in cost function $\left(f_{2}\right)$.

In all three scenarios a set of equations are obtained from EPR. However the initial suggested equations by the EPR do not include the effect of all three introduced input parameters. Also, the suggested models in the last ranks are suffered from complex structure. Obviously these equations are not appropriate for modelling the behaviour of the system. Therefore the following best models (Equations 15 and 16) are selected for calculation of total mass of solute $\left(f_{1}\right)$ in the three different scenarios considered based on performance of EPR models with the highest value of COD value and with the reasonable structure of the function (with the least possible number of terms). 
Developed model for ADR scenario

$$
\begin{aligned}
f_{1}= & -8461.723+1.142 \mathrm{YA}+1787.865 \mathrm{XA}^{0.5}-105.867 \mathrm{XA} \\
& +\left(1.101 * 10^{-1}\right) \mathrm{XA}^{2}-40.924 \mathrm{QA}^{0.5}+\left(2.617 * 10^{-1}\right) \mathrm{YAQA}^{0.5} \\
& +6240.890 \mathrm{QA}^{0.5} \mathrm{XA}^{-1}+\left(1.966 * 10^{-2}\right) \mathrm{QA}^{2}-166.891 \mathrm{YA}^{0.5} \mathrm{QA}^{2} \mathrm{XA}^{-2}
\end{aligned}
$$

Developed model for both ADRTWW and ADsRTWW scenarios

$$
\begin{aligned}
f_{1}= & 30.966-24.936 \mathrm{YA}^{0.5}+7.827 \mathrm{YA}-\left(7.053 * 10^{-2}\right) \mathrm{YA}^{2} \\
& +56.411 \mathrm{QA}^{-1}-12.204 \mathrm{YA}^{0.5} \mathrm{QA}^{-1}+343412.244 \mathrm{QA}^{0.5} \mathrm{XA}^{-2} \\
& -2.069 \mathrm{QA}+\left(2.605 * 10^{-2}\right) \mathrm{QA}^{2}-105.069 \mathrm{YA}^{0.5} \mathrm{QA}^{2} \mathrm{XA}^{-2}
\end{aligned}
$$

Figure 8 compare the predicted values of $f_{1}$ by the proposed EPR models with the numerically calculated values for both training and validation stages. There are very good correlations between the results. Figure 9 show the optimal results of the S/O process of the management models using both EPR-GA and FE-GA. It could be observed that the new nondominated front obtained using the EPR-GA is very close to and slightly has better distribution than the frontiers obtained from FE-GA. Despite the same metamolde (Equation 16) has been used for both ADRTWW and ADsRTWW scenarios, the general pattern of the results in ADRTWW is more influenced by the nonlinear nature of the problem and the process; where its optimal results show a less agreements compared to the optimal results of ADsRTWW scenario.

\subsection{Computational efficiency of each S/O me thodology}

In both schemes of the S/O, the optimization model (NSGA-II) uses the following parameters to randomly generate decision variables: population size $=50$, total number of generations $=100$, probability of crossover $=0.9$ and probability of mutation $=0.0025$.

The multiple calls of the simulation model (consists of nonlinear and difficult to solve coupled equations of the flow and solute transport) in the optimization framework make the S/O method by FE-GA to be computationally inefficient. Moreover, the fine spatial and temporal discretization of unsaturated flow simulation to limit the instability and oscillatory results intensifies the computational complexity of the process. The total computational time of the analysis by FE-GA was about 16 days on an Intel(R) Core(TM) i7-2600 CPU @ $3.40 \mathrm{GHz}$ (8 CPUs) with $16 \mathrm{~GB}$ RAM in this small aquifer system. However the total time of the EPR-GA was about $1 \mathrm{sec}$. And the average time required the generations of database of size 500 was about 1.5 days. Therefore by including the later time the overall average time in EPR-GA is about $10 \%$ of the time used by FE-GA. Therefore the beneficial aspects of the using EPR emerge in significantly reducing the computational burden. 

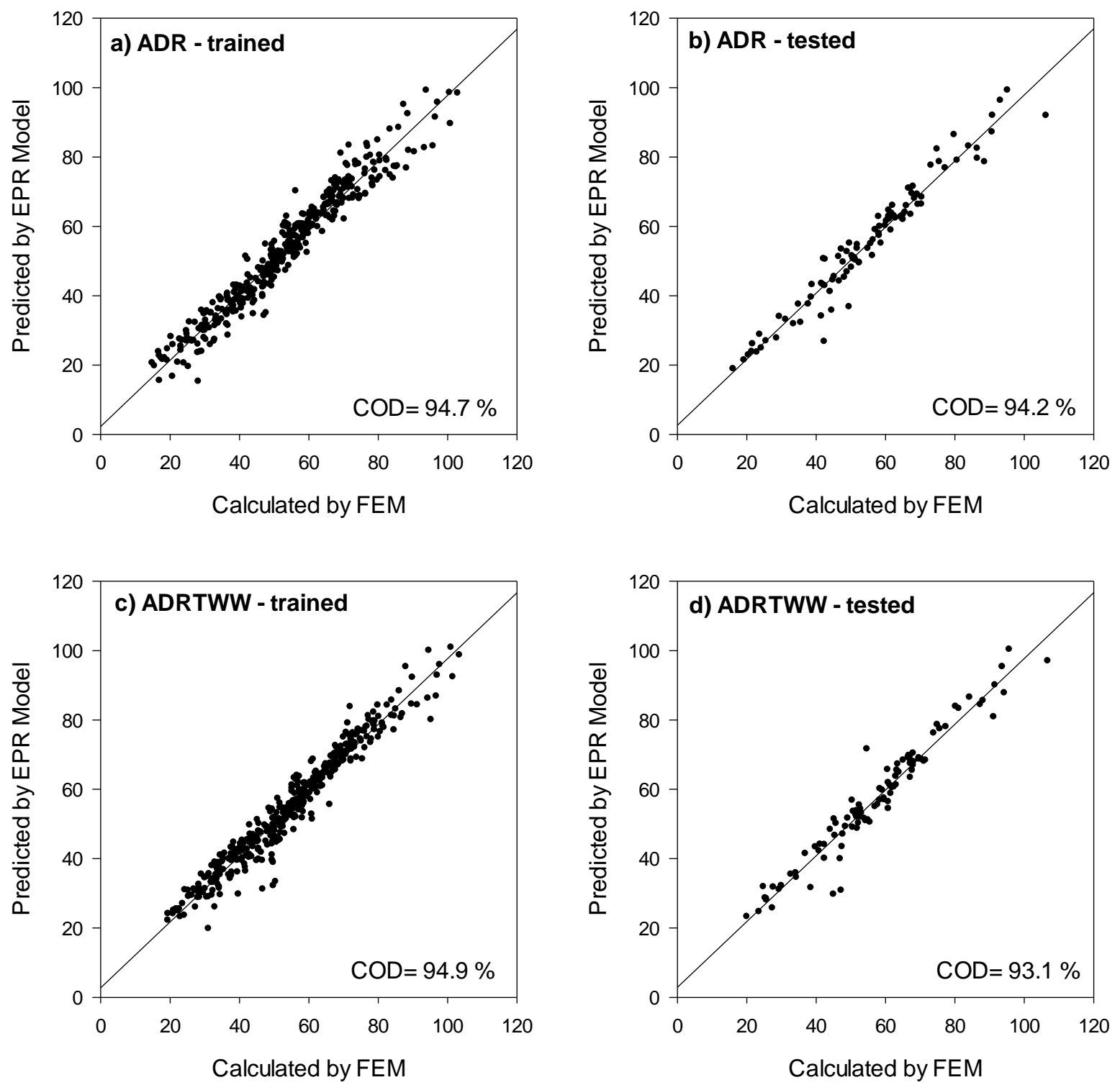

Figure 8: Comparison of the $\mathrm{f}_{1}$-values predicted by developed EPR models with their measured results by FE in each control scenario. 

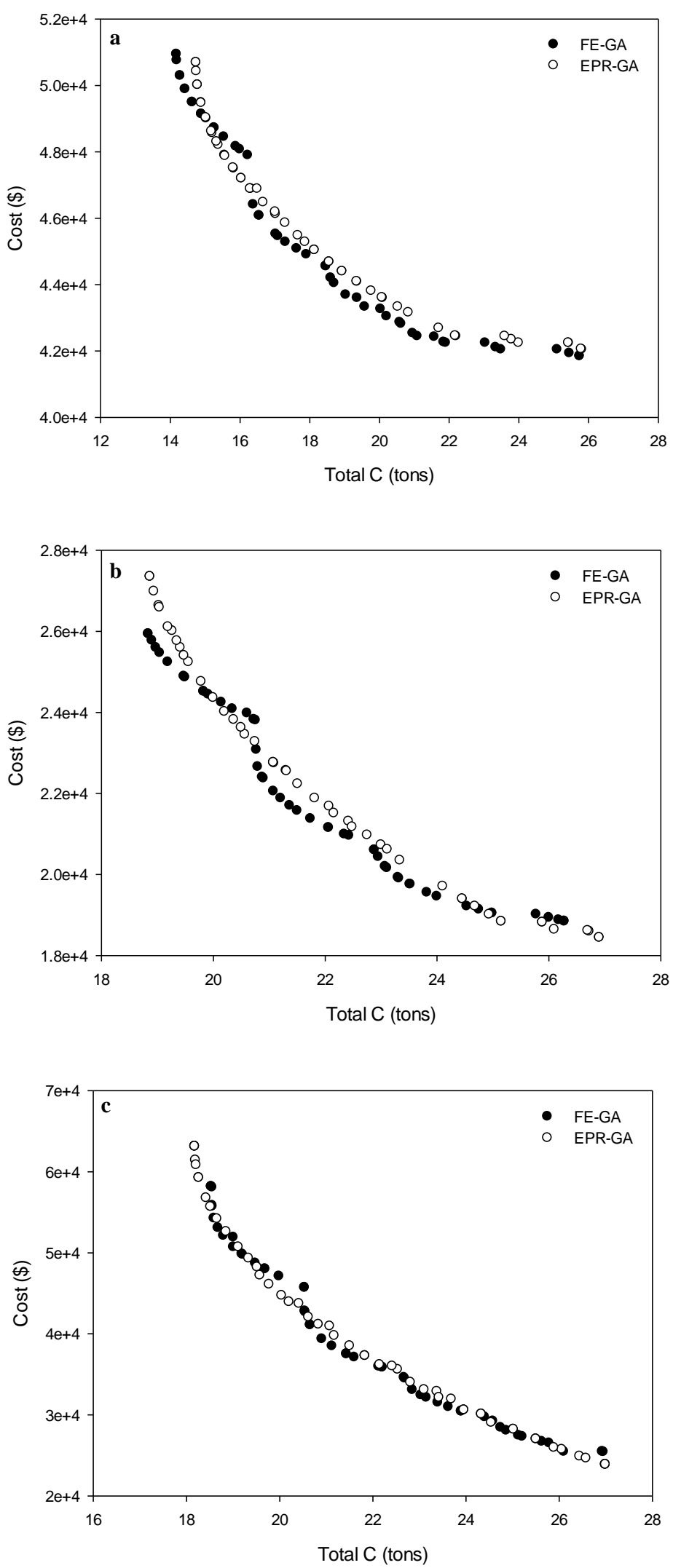

Figure 9: Comparison of optimal solutions obtained by FE-GA with EPR-GA for management scenarios a) ADR, b) ADRTWW and c) ADsRTWW. 


\section{Sensitivity analyses}

The good performances behave of the developed mathematical equations representing the response of the system during the $\mathrm{S} / \mathrm{O}$ encourage the study to use them in order to quick investigate the impacts of different management factors on the overall optimal results of the management scenarios as sensitivity analysis. For this purpose the effects of different values of the recovery ratio (of the desalination plant) and the cost impacts of supplying recharge water from different external sources on the progress of ADRTWW scenario is investigated using EPR-GA technique in two separate studies. The reason for choosing the ADRTWW is that this scenario is proposed by the current work as the cost-effective methodology to control SWI and also it already uses the external source of water (TWW) for recharging purposes in its specifications.

\subsection{Effects of recovery ratios on optimal results}

The effects of desalination recovery ratio on the optimal solutions are investigated by studying the ADRTWW scenario at five different recovery ratios 40, 50, 60, 65 and 70 percent. The results of the EPR-GA clearly indicate that the cost decreases significantly with increasing the recovery ratio (Figure 10). By increasing the recovery ratio the GA algorithm is forced to search in domain that constitutes large rates of pumping to get the maximum efficiency. Based on the definition of the recovery ratio the increasing of the total produced water from desalination plant is associated with increasing of the recovery ratio. Therefore the GA tries to use the provided opportunity to guide the management process and the abstraction well to pump the brackish water as much as possible to earn the highest rate of profit corresponding to the market price of produced desalinated water. By application of EPR-GA in sensitivity analysis the good overview of the optimal results are obtained in short period of time without any complexity in computational process.

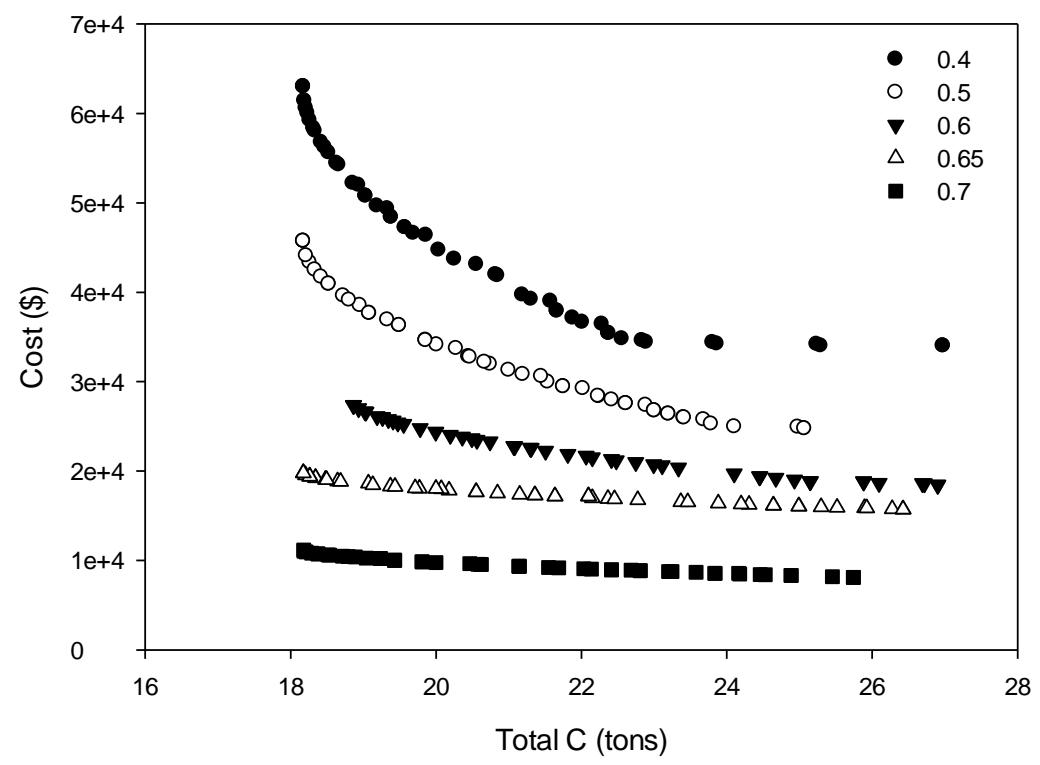

Figure 10: Trade-off curves for various recovery ratios in ADRTWW scenario. 


\subsection{Cost-dependency impacts of supplying the recharge wate $r$ from diffe re nt sources}

Purchase water from a municipal water supplier or from TWW plant, use surface wastewater with low TDS (lakes, rivers) and collect and use rainwater are considered as the three main sources of water which may provide the water for recharge system in reasonable cost than use of desalinated water. By focusing on market price and supplying cost of water from these sources the second objective function $\left(\mathrm{f}_{2}\right)$ of the ADRTWW can be modified to represent three different new schemes correspond to these three cheap sources of the water. The first scheme is the ADRTWW itself which are presented before and it is based on providing the TWW from the first source of water. The TWW is supplied (purchased and delivered) commercially into the recharge basin $\left(\mathrm{CTWQ}=0.25 \$ / \mathrm{m}^{3}, \mathrm{CRQ}=0.12 \$ / \mathrm{m}^{3}\right)$.

In the second scheme the water is collected from the natural sources (river or lakes) and only the transferring cost is being counted in $\mathrm{f}_{2}\left(\mathrm{CTWQ}=0.0 \$ / \mathrm{m}^{3}, \mathrm{CRQ}=0.12 \$ / \mathrm{m}^{3}\right)$. And finally the priceless collecting of the storm water in subsurface pond (CTWQ=0.0 $\$ / \mathrm{m}^{3}, \mathrm{CRQ}=0.0$ $\$ / \mathrm{m}^{3}$ ) is the third scheme of this parametric study that will assessed through the EPR-GA. For comparison purposes the TDS of the supplied recharge water in all three schemes are considered to be equivalent to $1300 \mathrm{mg} / \mathrm{l}$ which is the level has been used for identification of TWW in this work.

By considering the new cost terms defined in each schemes the optimal results in terms of the objective functions $f_{1}$ and $f_{2}$ are investigated and the resulted Pareto frontiers are illustrated in Figure 11. The comparisons among the trade-off curves indicated significant positive trend and enhancing in the cost efficiency of the recharge by ponding the rainwater on the overall optimal results of the unconfined aquifer. Improvement of water quality, restoration of groundwater levels and control of saline water intrusion in aquifer are the three main benefits concluded from application of storm water, TWW or other potable sources of water for artificial recharging of the unconfined coastal aquifer.

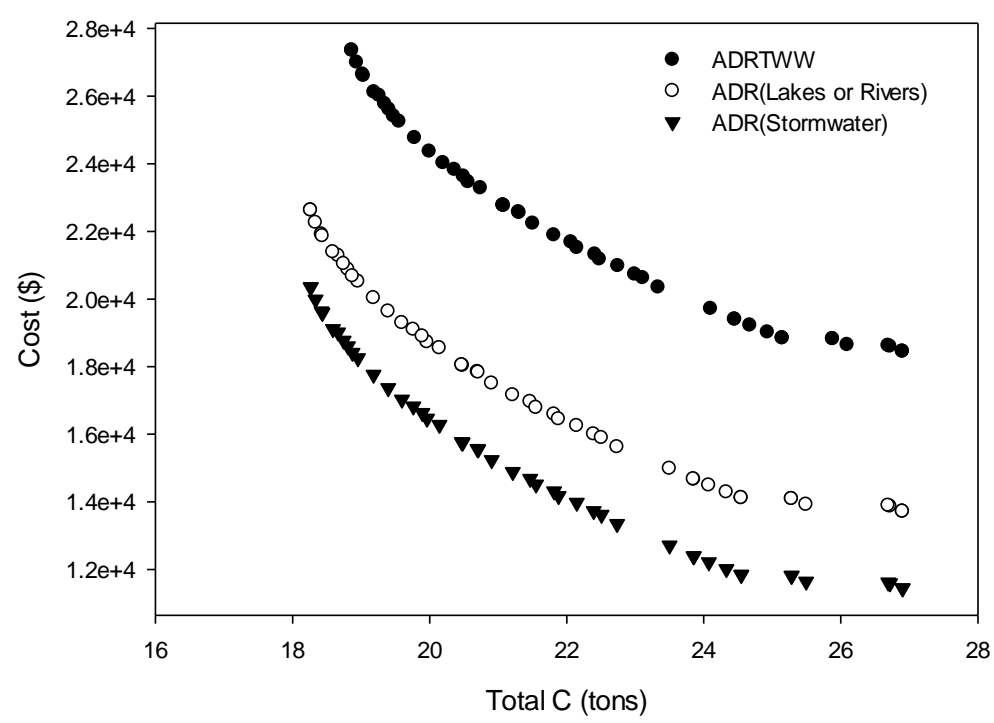

Figure 11: Effects of different recharge sources on optimal solutions. 


\section{Conclusions}

In this paper a novel approach for modelling the complex response of the aquifer system using evolutionary polynomial regression (EPR) is presented. The EPR is one of data-driven technique used to characterize the functional relationship between the system inputs and outputs and represent this relationship in mathematical or symbolic structures includes constant and exponents.

The EPR used to derive functions describing the response of the aquifer system to different pumping rates in two different particular studies. In first study the potential of the EPR in evaluating the toe location of the saltwater wedge has been highlighted as the response of the aquifer and in second study the model is integrated with multi objective optimization algorithm as alternative for the numerical simulation model. The both studies are carried out on 2D descriptive aquifer with proper initial and boundary conditions. The developed models are trained/tested on the FE database obtained by multi-running of the numerical simulation model. The developed models present a structured and transparent representation of the aquifer system which is allowing a physical interpretation of its response to various contributing parameters.

The results show that EPR model has potential to capture satisfactorily the nonlinear behaviour of the aquifer system subjected to artificial man-made disturbance (abstraction). In second study three different coupled management scenarios to control SWI and to protect the quality of the water at the location of the available production well have been assessed using the S/O methodology. The S/O models employed in to address the efficiency of each of management scenario in terms of the cost and the amount salinity in the aquifer by directly linking of the numerical simulation model to optimization algorithm (FE-GA).

However, the good performance behave of the EPR in the first study and also the huge computational burden imposed by FE-GA promote to develop another set of EPR models appropriate for each management strategy and integrate them with optimization tool in order to seek the Pareto frontiers of the system in each management scenarios (EPR-GA).

Comparison of the results between these two schemes of the S/O shows that the developed EPR models provide accurate predictions for the optimal solutions. Also the proposed method identified a slightly better distribution of the optimal solutions along the Paretofrontiers than the one obtained from optimization relying on the numerical model. Implementation of this surrogate models in the $\mathrm{S} / \mathrm{O}$ framework resulted in significant reduction in CPU time comparing to the computational time used by FE-GA. This can be considered as the main benefit of the application of the EPR in optimization of the computationally complex problems such as density dependent flow problems under the effects of unsaturated zone.

A new integrated methodology ADRTWW was proposed to control SWI in unconfined aquifers. The main distinguishing feature of ADRTWW is to collect TWW in percolation ponds and use it as the source of recharge instead of deep injection. The results show that for the case study considered, the proposed methodology controls SWI with the least cost and least salt concentration.

In two different parametric studies the effects of different recovery ratios of the desalination plant and the cost impacts of different practical source of the recharge water on the optimal 
results are investigated based on the developed EPR-GA approach. In the first study of sensitivity analysis, results show the positive impacts of the increasing recovery ratios on the overall trend of the Pareto frontiers and in second study the work confirmed that the collection of the storm water in subsurface basin is the more efficient method than other commercial method of supplying recharge water supplying. In conclusion the main contribution of this work is the application EPR as surrogate model for the first time in simulation and S/O of the aquifer system subjected to SWI. It is worth mention that the all proposed EPR equations are specified for the aquifer considered in this work and cannot be used for the other case studies. However the methodology is general and can be used in other systems to find their responses.

\section{References}

Abazza, H., 2012. Economic considerations for sustainable water integrated management, Sustainable Water Integrated Management-Support Mechanism (SWIM- SM), http://www.swim-sm.eu.

Ahangar-Asr, A., Faramarzi, A., Javadi, A.A., 2010. A new approach for prediction of the stability of soil and rock slopes. Engineering Computations, 27(7): 878 - 893.

Ahangar-Asr, A., Johari, A., Javadi, A.A., 2012. An evolutionary approach to modelling the soilwater characteristic curve in unsaturated soils. Computers \& Geosciences, 43(0): 25-33.

Asano, T., Bahri, A., 2010. Global challenges to wastewater reclamation and reuse. Selections from the 2010 World Water Week in Stockholm: Edited by Jan Lundqvist: 64-72.

Ataie-Ashtiani, B., Volker, R.E., Lockington, D.A., 1999. Tidal effects on sea water intrusion in unconfined aquifers. Journal of Hydrology, 216(1-2): 17-31.

Banks, H.O., Richter, R.C., 1953. Sea-water intrusion into ground-water basins bordering the California coast and inland bays. Transactions, American Geophysical Union, 34: 575-582.

Bear, J., Zhou, Q., 2007. Sea water intrusion into coastal aquifers. In: Delleur, J.W. (Ed.), The handbook of groundwater engineering. CRC Press,T aylor \& Francis Group, Boca Raton, Florida., pp. 12-1-12-29.

Bhattacharjya, R., Datta, B., 2005. Optimal Management of Coastal Aquifers Using Linked Simulation Optimization Approach. Water Resour Manage, 19(3): 295-320.

Bhattacharjya, R., Datta, B., 2009. ANN-GA-Based Model for Multiple Objective Management of Coastal Aquifers. Journal of Water Resources Planning and Management, 135(5): 314-322.

Bray, B., Yeh, W., 2008. Improving Seawater Barrier Operation with Simulation Optimization in Southern California. Journal of Water Resources Planning and Management, 134(2): 171-180.

Bruington, A.E., 1972. Saltwater intrusion into aquifers1. JAWRA Journal of the American Water Resources Association, 8(1): 150-160.

Chen, J.J. et al., 2003. Tertiary treatment of wastewater for reuse in Chin a, Proceedings of the Water Environment Federation,Technical Exhibition and Conference (WEFTEC). Water Environment Federation, Alexandria-Virginia, pp. Session 11 through Session 20:540-556.

Das, A., Datta, B., 1999a. Development of management models for sustainable use of coastal aquifers. Journal of irrigation and drainage engineering, 125(3): 112-121.

Das, A., Datta, B., 1999b. Development of Multiobjective Management Models for Coastal Aquifers. Journal of Water Resources Planning and Management, 125(2): 76-87.

Deb, K., Pratap, A., Agarwal, S., Meyarivan, T., 2002a. A fast and elitist multiobjective genetic algorithm: NSGA-II. IEEE Trans Evol Comput, 6(2): 182-197.

Deb, K., Pratap, A., Agarwal, S., Meyarivan, T., 2002b. A fast and elitist multiobjective genetic algorithm: NSGA-II. Evolutionary Computation, IEEE Transactions on, 6(2): 182-197.

Dhar, A., Datta, B., 2009. Salt water Intrusion Management of Coastal Aquifers. I: Linked SimulationOptimization. Journal of Hydrologic Engineering, 14(12): 1263-1272.

Faramarzi, A., Alani, A.M., Javadi, A.A., 2014. An EPR-based self-learning approach to material modelling. Computers \& Structures, 137(0): 63-71. 
Faramarzi, A., Javadi, A.A., Ahangar-Asr, A., 2013. Numerical implementation of EPR-based material models in finite element analysis. Computers \& Structures, 118(0): 100-108.

Giustolisi, O., Doglioni, A., Savic, D.A., di Pierro, F., 2008. An evolutionary multiobjective strategy for the effective management of groundwater resources. Water Resources Research, 44(1): W01403.

Giustolisi, O., Doglioni, A., Savic, D.A., Webb, B.W., 2007. A multi-model approach to analysis of environmental phenomena. Environmental Modelling \& Software, 22(5): 674-682.

Giustolisi, O., Savic, D.A., 2006. A symbolic data-driven technique based on evolutionary polynomial regression. Journal of Hydroinformatics, 8(3): 207-222.

Isaka, M., 2012. Water desalination using renewable energy, International Energy Agency (IEA) and The International Renewable Energy Agency (IRENA).

Javadi, A.A., Abd-Elhamid, H.F., Farmani, R., 2012. A simulation-optimization model to control seawater intrusion in coastal aquifers using abstraction/recharge wells. International Journal for Numerical and Analytical Methods in Geomechanics, 36(16): 1757-1779.

Kacimov, A.R., Sherif, M.M., 2006. Sharp interface, one-dimensional seawater intrusion into a confined aquifer with controlled pumping: Analytical solution. Water Resources Research, 42(6): W06501.

Kourakos, G., Mantoglou, A., 2009. Pumping optimization of coastal aquifers based on evolutionary algorithms and surrogate modular neural network models. Advances in Water Resources, 32(4): 507-521.

Kourakos, G., Mantoglou, A., 2011. Simulation and Multi-Objective Management of Coastal Aquifers in Semi-Arid Regions. Water Resour Manage, 25(4): 1063-1074.

Kourakos, G., Mantoglou, A., 2013. Development of a multi-objective optimization algorithm using surrogate models for coastal aquifer management. Journal of Hydrology, 479(0): 13-23.

Lin, J. et al., 2009. A genetic algorithm based groundwater simulation-optimization model under variable-density conditions, Trends and sustainability of groundwater in highly stressed aquifers. Proceedings of Symposium JS. 2 at the Joint Convention of the International Association of Hydrological Sciences (IAHS) and the International Association of Hydrogeologists (IAH) held in Hyderabad, India,September 2009. IAHS Press, pp. 223-232.

Patel, A.S., Shah, D.L., 2008. Water management: Conservation, harvesting and artificial recharge. New age international (p) limited, publishers.

Price, R.M., Herman, J.S., 1991. Geochemical investigation of salt-water intrusion into a coastal carbonate aquifer: Mallorca, Spain. Geological Society of America Bulletin, 103(10): 12701279.

Qahman, K., Larabi, A., Ouazar, D., Naji, A., Cheng, A.D., 2005. Optimal and sustainable extraction of groundwater in coastal aquifers. Stochastic Environmental Research and Risk Assessment, 19(2): 99-110.

Qahman, K., Larabi, A., Ouazar, D., Naji, A., Cheng, A.H.-D., 2009. Optimal extraction of groundwater in gaza coastal aquifer. Journal of Water Resource and Protection, 1(4): 249259.

Rao, S.V.N., Sreenivasulu, V., Bhallamudi, S.M., Thandaveswara, B.S., Sudheer, K.P., 2004. Planning groundwater development in coastal aquifers / Planification du développement de la ressource en eau souterraine des aquifères côtiers. Hydrological Sciences Journal, 49(1): 155 170.

Rezania, M., Faramarzi, A., Javadi, A.A., 2011. An evolutionary based approach for assessment of earthquake-induced soil liquefaction and lateral displacement. Engineering Applications of Artificial Intelligence, 24(1): 142-153.

Rezania, M., Javadi, A.A., Giustolisi, O., 2008. An evolutionary-based data mining technique for assessment of civil engineering systems. Engineering Computations, 25(6): 500 - 517.

Sherif, M., Hamza, K., 2001. Mitigation of Seawater Intrusion by Pumping Brackish Water. Transport in Porous Media, 43(1): 29-44.

Sherif, M.M., Singh, V.P., Amer, A.M., 1990a. A note on saltwater intrusion in coastal a quifers. Water Resour Manage, 4(2): 123-134.

Sherif, M.M., Singh, V.P., Amer, A.M., 1990b. A sensitivity analysis of '2D-FED', a model for seawater encroachment in leaky coastal aquifers. Journal of Hydrology, 118(1-4): 343-356. 
Singh, R.P., 2013. Water Desalination" The Role of RO and MSF. IOSR Journal of Environmental Science, Toxicology And Food Technology (IOSR-JEST FT), 6(2): 61-65.

Sorek, S., Pinder, G.F., 1999. Survey of Computer Codes and Case Histories. In: Bear, J., Cheng, A.D., Sorek, S., Ouazar, D., Herrera, I. (Eds.), Seawater Intrusion in Coastal Aquifers Concepts, Methods and Practices. Theory and Applications of Transport in Porous Media. Springer Netherlands, pp. 399-461.

Sreekanth, J., Datta, B., 2010. Multi-objective management of salt water intrusion in coastal aquifers using genetic programming and modular neural network based surrogate models. Journal of Hydrology, 393(3-4): 245-256.

Sreekanth, J., Datta, B., 2011 a. Comparative Evaluation of Genetic Programming and Neural Network as Potential Surrogate Models for Coastal Aquifer Management. Water Resour Manage, 25(13): 3201-3218.

Sreekanth, J., Datta, B., 2011b. Coupled simulation-optimization model for coastal aquifer management using genetic programming-based ensemble surrogate models and multiplerealization optimization. Water Resources Research, 47(4): W04516.

Todd, D.K., 1974. Salt-Water Intrusion and Its Control. Journal (American Water Works Association), 66(3): 180-187.

Van Dam, J.C., 1999. Exploitation, Restoration and Management. In: Bear, J., Cheng, A.D., Sorek, S., Ouazar, D., Herrera, I. (Eds.), Seawater Intrusion in Coastal Aquifers - Concepts, Methods and Practices. Theory and Applications of Transport in Porous Media. Springer Netherlands, pp. 73-125.

Van Genuchten, M.T., 1980. A closed-form equation for predicting the hydraulic conductivity of unsaturated soils. Soil Science Society of America Journal, 44(5): 892-898.

Voss, C.I., 1984. A finite-element simulation model for saturated-unsaturated, fluid-densitydependent ground-water flow with energy transport or chemically-reactive single-species solute transport. 84-4369, U.S. Geol. Surv. (USGS), Water Resour. Invest.

Voss , C.I., Provost, A.M., 2010. SUT RA-A model for saturated-unsaturated variable-density groundwater flow with solute or energy transport. 02-4231, U.S. Geol. Surv. (USGS), Water Resour. Invest.

Wicks, C.M., Herman, J.S., 1995. The Effect of Zones of High Porosity and Permeability on the Configuration of the Saline-Freshwater Mixing Zone. Ground Water, 33(5): 733-740. 